\title{
THEORETICAL STUDY ON ELECTRONIC STRUCTURES AND SPECTROSCOPY OF TRIARYLBORANE SUBSTITUTED BY THIOPHENE
}

\author{
Ye Zhang ${ }^{1,2}$, Ting $\operatorname{Li}^{1}$ and Qiwen Teng ${ }^{1 *}$ \\ ${ }^{1}$ Department of Chemistry, Zhejiang University, Hangzhou 310027, P.R. China \\ ${ }^{2}$ Department of Basic Chemistry, Faculty of Pharmacology, Dali, Yunnan 671000, P.R. China
}

(Received November 17, 2007; revised November 22, 2008)

\begin{abstract}
The electronic structures of a series of triarylborane derivatives were studied using the AM1 method and density function theory (DFT) at B3LYP/6-31G(d) level. Based on the B3LYP/6-31G(d) optimized geometries, the electronic spectra, IR and ${ }^{13} \mathrm{C}$ NMR spectra of these compounds were calculated with the INDO/CIS, AM1 and B3LYP/6-31G(d) methods, respectively. The presence of electron-donating alkyl groups and the increase in the number of thiophene rings in the derivatives lead to the decrease in LUMO-HOMO energy gaps. At the same time, the first absorptions in the electronic spectra and the stretching vibrations of the C-C as well as $\mathrm{C}-\mathrm{H}$ bonds in the IR spectra of these compounds compared with those of the parent compound are redshifted. Also, the ${ }^{13} \mathrm{C}$ chemical shifts of the carbon atoms on the phenyl rings in these compounds are upfield relative to those of the same carbon atoms in the parent compound.
\end{abstract}

KEY WORDS: Triarylborane, LUMO-HOMO energy gaps, Red-shift, B3LYP/6-31G(d)

\section{INTRODUCTION}

Luminescent materials $[1,2]$ have extensive applications in medical diagnostics, molecular biology, aviation, and material science. The incorporation of boron atoms into extended organic $\pi$-systems is widely studied due to intriguing electronic and photophysical properties. These properties are commonly arisen from the overlap between the empty p-orbital on the boron atoms and the conjugated $\pi$-system. Some techniques for incorporating the boron atoms into the backbone of polymers have also been reported [3-5]. Chujo et al. have introduced the electrondeficient boron atom to the conjugated skeleton to form organoboron polymers [6]. These polymers show typical light-emitting properties and may even act as novel $n$-type polymers in electronic devices [7,8]. It is noted that tetracoordinated boron centers exist in the luminescent organoboron polymers [9]. The boron centers in the compounds can be attached to two either similar or dissimilar acetylenic units which are incorporated using chromophores such as anthracene. These compounds exhibit fascinating fluorescent and redox characters [10]. There are few theoretical studies on electronic structures and spectroscopy of the triarylborane compounds.

Some of these derivatives have been synthesized and characterized by Parab et al. [11]. They have indicated that the stability and Lewis acidity of boron sites are changed through modifications [11]. Lewis acidic organoboron groups possess the affinity to nucleophiles. The fluorescence of organoboron compounds can be adjusted by increasing the number of thiophene rings in the matrix. Based on the synthetic experiment of Parab et al. [11], we have designed a series of computation models for triarylborane compounds. The effects of the electron-donating substituents and growing thiophene rings on the electronic structures and spectroscopic properties of the compounds are explored in the passage.

*Corresponding author. E-mail: wushi@zju.edu.cn 


\section{CALCULATION METHODS}

In the experiment of Parab et al. [11], triarylborane $\mathrm{BPh}_{3}$ substituted by $\mathrm{C}\left(\mathrm{CH}_{3}\right)_{3}$ has been synthesized. In order to inspect the effect of the bulky group $\mathrm{C}\left(\mathrm{CH}_{3}\right)_{3}$, triarylborane $\mathrm{BPh}_{3}$ (compound 1) is used as a matrix, and compounds 2-5 are designed by changing the substituent $\mathrm{R}$ into methyl, ethyl, isopropyl, and butyl, respectively, shown in Figure 1. As result of a good fluorescent character of a thiophene ring, compound 6 is formed by changing one of the aryl ring in $\mathrm{BPh}_{3}$ into the thiophene ring $\left(\mathrm{SC}_{4} \mathrm{H}_{3}\right)$. Compounds 7-9 are formed by increasing the number of the thiophene rings from 1 to 3 on R1. These thiophene rings are connected with each other via 2-linkage, and the sulfur atoms in the rings are located at the top or the bottom alternatively. Compounds 10 and 11 are formed by changing the group R1 on the matrix of compound 6 so as to explore the influence of electron-donating groups. Compounds 12 and 13 are formed by replacing the aryl rings in $\mathrm{BPh}_{3}$ using two and three thiophene rings. The AM1 [12] and B3LYP methods [13,14] are successfully used to study the electronic structures and IR frequencies of the supra-molecular aggregates [15-18], the ${ }^{13} \mathrm{C}$ chemical shifts of the amino acids [19], the catalytic reactions [20], and the properties of the other organic compounds [21]. In view of computation time and accuracy, the AM1 method is first used, followed by B3LYP method with 6-31G(d) basis set in density function theory (DFT). Full geometry optimization of these compounds without any symmetric restriction is performed using the AM1 method and DFT at B3LYP/6-31G(d) level in GAUSSIAN 03 program package [22]. The equilibrium geometries with the minimum energies of the compounds are achieved. According to Koopmans' theorem, vertical ionization potential (IP) is approximately defined as the negative value of the HOMO (the highest occupied molecular orbital) energy. The vertical electron affinity (EA) is approximately defined as the negative value of the LUMO (the lowest unoccupied molecular orbital) energy. The absolute hardness $(\eta)$ is equal to the half of the difference between IP and EA. The absolute electron negativity $(\chi)$ is defined as the half of the sum for IP and EA. All these values are calculated at the B3LYP/6-31G(d) level.

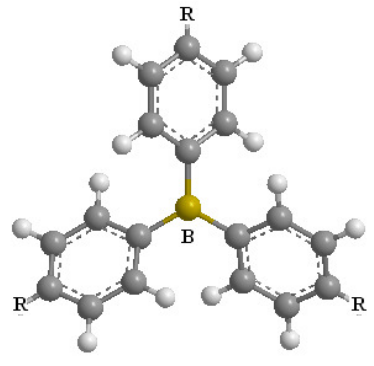

(a) Compounds 1-5

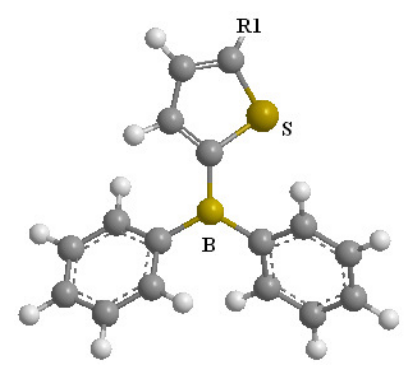

(b) Compounds 6-11

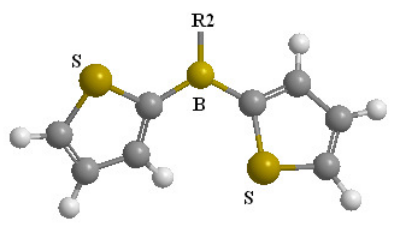

(c) Compounds 12-13

Compound 1: $\mathrm{R}=\mathrm{H}$; Compound 2: $\mathrm{R}=\mathrm{CH}_{3}$; Compound 3: $\mathrm{R}=\mathrm{C}_{2} \mathrm{H}_{5}$; Compound 4: $\mathrm{R}=$ $\mathrm{CH}\left(\mathrm{CH}_{3}\right)_{2}$; Compound 5: $\mathrm{R}=\mathrm{C}\left(\mathrm{CH}_{3}\right)_{3}$; Compound 6: $\mathrm{R} 1=\mathrm{H}$; Compound 7: $\mathrm{R} 1=$ thiophene $\left(\mathrm{SC}_{4} \mathrm{H}_{3}\right)$; Compound 8: $\mathrm{R} 1=\left(\mathrm{SC}_{4} \mathrm{H}_{2}\right)_{2} \mathrm{H}$; Compound 9: $\mathrm{R} 1=\left(\mathrm{SC}_{4} \mathrm{H}_{2}\right)_{3} \mathrm{H}$; Compound 10: $\mathrm{R} 1=$ $\left(\mathrm{SC}_{4} \mathrm{H}_{2}\right) \mathrm{N}\left(\mathrm{C}_{6} \mathrm{H}_{5}\right)_{2}$; Compound 11: $\mathrm{R} 1=\left(\mathrm{SC}_{4} \mathrm{H}_{2}\right) \mathrm{NH}_{2}$; Compound 12: $\mathrm{R} 2$ = phenylene; Compound 13: $\mathrm{R} 2=\mathrm{SC}_{4} \mathrm{H}_{3}$.

Figure 1. The structural schemes of compounds 1-13 studied in the passage. 
Based on the B3LYP/6-31G(d) optimized geometries of the compounds, the configuration interaction was investigated by the INDO/CIS method [23] without any adjustment of parameters [24-28]. There are 197 configurations produced by exciting electrons from the 14 HOMOs into the 14 LUMOs, including the ground state. The frequencies in the IR spectra and the chemical shifts in the ${ }^{13} \mathrm{C}$ NMR spectra of the compounds are computed using the AM1 method and GIAO method at the B3LYP/6-31G(d) level, respectively.

\section{RESULTS AND DISCUSSION}

\section{The electronic structures at the ground state}

The energy gaps of compounds 1-13 are illustrated in Table 1. The energy gaps of compounds 2-5 are less than that of compound 1 since the conjugation system is elongated appropriately by the super conjugation effect between the alkyl groups and phenyl rings in compounds 2-5. The energy gaps of compounds 6-9 are gradually decreased. The number of the thiophene rings on the matrix is increased, thus the conjugation system is enlarged. The energy gap of compound 10 is $2.9965 \mathrm{eV}$, which is accordant with the value $2.65 \mathrm{eV}$ calculated using TD-DFT (B3LYP) [11]. The energy gap of compound 10 is less than that of compound 11 because the conjugation system is amplified owing to the presence of the two phenyl rings on the $\mathrm{N}$ atom in compound 10. Likewise, the energy gap of compound 11 is narrower than that of compound 7, which is caused by the super conjugation effect between the group $-\mathrm{NH}_{2}$ and thiophene rings. The electrons in these compounds compared with those of compound 1 are easier to be excited, and the fluorescent wavelengths are red-shifted. These compounds are more reactive. It has been shown that the HOMO energy of the complex is increased, which reduces the LUMO-HOMO energy gap when the electron-donating group exists [29]. Jenkins et al. have also pointed out that the energy gap is decreased as the chain is elongated [30]. These are compatible with our calculation results.

The energy gaps of compounds 1, 6, 12 and 13 are gradually decreased, and thus the fluorescent wavelengths will be red-shifted since the phenyl rings are replaced by the thiophene rings one by one. This is ascribed to the large radius and the remarkable distortion of electron cloud of the $\mathrm{S}$ atom as well as the weakening of the conjugation effect in the presence of the weak S-C bonds.

Table 1. Several B3LYP/6-31G(d) optimized parameters (eV) of compounds 1-13.

\begin{tabular}{|c|c|c|c|c|c|c|c|}
\hline Compounds & E $_{\text {номо }}$ & E $_{\text {Luмо }}$ & Energy gap & IP & EA & $\eta$ & $\chi$ \\
\hline 1 & -6.559 & -1.711 & 4.848 & 6.559 & 1.711 & 2.424 & 4.135 \\
\hline 2 & -6.240 & -1.541 & 4.699 & 6.240 & 1.541 & 2.350 & 3.891 \\
\hline 3 & -6.255 & -1.558 & 4.697 & 6.255 & 1.558 & 2.349 & 3.906 \\
\hline 4 & -6.252 & -1.556 & 4.696 & 6.252 & 1.556 & 2.348 & 3.904 \\
\hline 5 & -6.229 & -1.547 & 4.682 & 6.229 & 1.547 & 2.341 & 3.888 \\
\hline 6 & -6.328 & -1.785 & 4.543 & 6.328 & 1.785 & 2.272 & 4.056 \\
\hline 7 & -5.624 & -2.003 & 3.621 & 5.624 & 2.003 & 1.811 & 3.814 \\
\hline 8 & -5.284 & -2.143 & 3.141 & 5.284 & 2.143 & 1.571 & 3.714 \\
\hline 9 & -5.097 & -2.234 & 2.863 & 5.097 & 2.234 & 1.432 & 3.665 \\
\hline 10 & -4.949 & -1.952 & 2.997 & 4.949 & 1.952 & 1.499 & 3.450 \\
\hline 11 & -5.025 & -1.807 & 3.218 & 5.025 & 1.807 & 1.609 & 3.416 \\
\hline 12 & -6.202 & -1.856 & 4.346 & 6.202 & 1.856 & 2.173 & 4.029 \\
\hline 13 & -6.205 & -1.905 & 4.300 & 6.205 & 1.905 & 2.150 & 4.055 \\
\hline
\end{tabular}




\section{The several important variables}

Ionization potential and absolute electro-negativity of compound 1 are the highest (Table 1 ). There is no distinct difference in the values of IP and $\chi$ of compounds $2-5$, which are lower than those of compound 1. The presence of the alkyl groups in compounds 2-5 increases the reductive abilities of the derivatives. The values of IP for compounds 7-11 are low, thus the electrons in the HOMOs of these compounds are easily lost. The electron affinities of compounds 2-5 are lower than that of compound 1. These compounds are less likely to gain electrons because the electron density on the phenyl rings is elevated in the presence of the alkyl groups. The data of EA for compounds 6-9 are enhanced with the increase in the number of the thiophene rings. This is arisen from the electron-withdrawing character of the $\mathrm{S}$ atoms. Similarly, the values of EA for compounds 6,12 and 13 are also augmented. The values of absolute hardness $(\eta)$ of compounds 7-11 are smaller, which leads to their smaller stabilities.

\section{The electronic spectra}

The first absorption in the electronic spectrum of compound 1 appears at $279.0 \mathrm{~nm}$, which corresponds to the $\mathrm{B}$ band of phenyl rings. The absorptions near $200 \mathrm{~nm}$ of compound 1 are arisen from the $\mathrm{E}$ band of phenyl rings (Figure 2). The first absorptions in the electronic spectra of compounds 2-9 are red-shifted compared to that of compound 1, which is ascribed to their narrow energy gaps. The $\mathrm{E}$ bands of the phenyl rings in these compounds are little changed, and the small influence of the alkyl groups is exerted upon the phenyl rings. The first absorption peaks at $308.5,380.3,433.0$ and $473.3 \mathrm{~nm}$ of compounds 6-9 are successively red-shifted. These absorptions are symmetry-allowed, and ascribed as the $\pi-\pi^{*}$ electronic transitions from the HOMOs to LUMOs. The gradual increase in the intensities of these absorptions indicates the growing fluorescent intensities. The red-shift in the wavelengths and elevation in the intensities of the above absorptions are caused by the increase in the number of the thiophene rings and enlargement of the conjugated system in compounds 6-9. The first absorption peaks of compounds 7 and 10 come out at 380.3 and $430.0 \mathrm{~nm}$, which is in agreement with the experimental results (373 and $432 \mathrm{~nm}$ ) [11], respectively. The p- $\pi$ conjugation between the lone pair of the electrons on the nitrogen atom and the $\pi$ electrons on the thiophene ring also leads to the extension of the conjugation system in compounds 10 and 11 . Then their first absorptions are red-shifted relative to that of compound 7 . The greater red-shift in the first absorption in compound 10 is resulted from the transannular conjugation effect between the two phenyl rings on the nitrogen atom and thiophene ring. Analogously, with the increase in the number of the thiophene rings, the first absorptions (308.5, 331.3 and $339.6 \mathrm{~nm}$ ) of compounds 6,12 and 13 are red-shifted in turn.
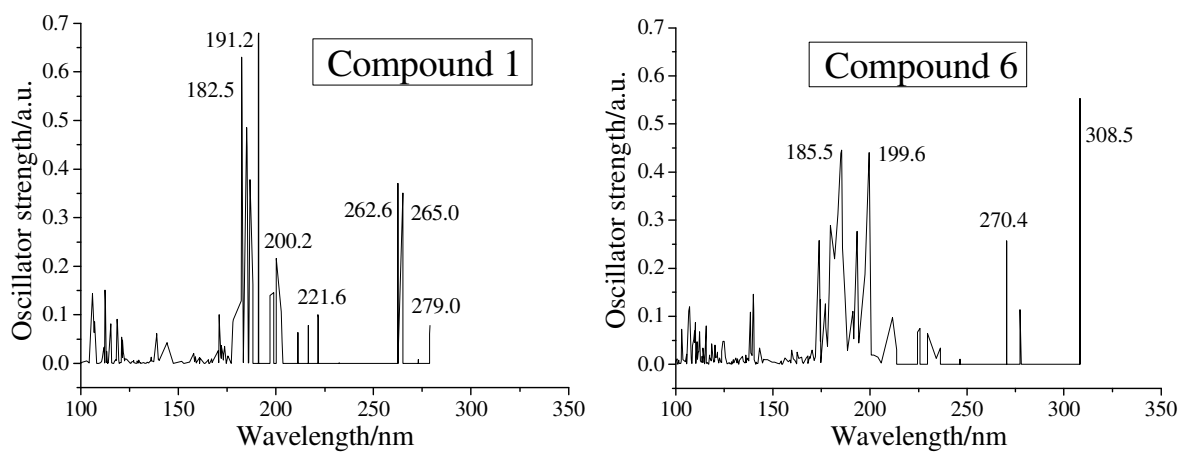

Figure 2. The electronic spectra of compounds 1 and 6. 
The IR spectra

The first absorption peak in the IR spectrum of compound 1 appears at $3282.1 \mathrm{~cm}^{-1}$, which is caused by the stretching vibrations of the $\mathrm{C}-\mathrm{H}$ bonds. The peaks at $1500-1700 \mathrm{~cm}^{-1}$ indicate the stretching vibrations of the $\mathrm{C}=\mathrm{C}$ bonds. The peaks between 1000 and $1500 \mathrm{~cm}^{-1}$ exhibit the stretching vibrations of C-B and C-C bonds. Those within $600-1000 \mathrm{~cm}^{-1}$ are ascribed as the bending vibrations of the $\mathrm{C}-\mathrm{H}$ bonds in compound 1 . The strongest peak of compound 1 appears at $1318.2 \mathrm{~cm}^{-1}$. The IR spectra of compounds $2-5$ are analogous. The intensities of the stretching and bending vibrations of the $\mathrm{C}-\mathrm{H}$ bonds in compounds $2-5$ are reduced, whereas those of the $\mathrm{C}=\mathrm{C}$ and $\mathrm{C}-\mathrm{B}$ bonds are amplified relative to those of compound 1 . The first absorptions (3278.9, 3279.0, 3278.3 and $\left.3276.5 \mathrm{~cm}^{-1}\right)$ and strongest peaks $(1237.6,1234.4,1216.4$ and $1275.8 \mathrm{~cm}^{-1}$ ) of compounds $2-5$ are red-shifted in contrast to those of compound 1 . This is caused by the extension of the conjugation system with the growing super-conjugation effect of the alkyl groups.

The first peaks $\left(3287.2,3303.8,3298.1\right.$ and $\left.3303.7 \mathrm{~cm}^{-1}\right)$ of compounds 6-9 are red-shifted in comparison with that of compound 1 . The electron density on the thiophene rings in compounds 6-9 is decreased and the stretching vibrations of the $\mathrm{C}-\mathrm{H}$ bonds are weakened owing to the electron-withdrawing property of the sulfur atom when the number of the thiophene rings is increased. The peaks within $1700-1500$ and $1300-1100 \mathrm{~cm}^{-1}$ of compounds 6-9 relative to those of compound 1 are strengthened, which are attributed to the increasing $\mathrm{C}=\mathrm{C}$ and $\mathrm{C}-\mathrm{S}$ bonds on the thiophene rings. The number of absorption peaks between 1500 and $600 \mathrm{~cm}^{-1}$ of compounds 6-9 is increased due to the lower symmetry.

Compared with the $1629.2 \mathrm{~cm}^{-1}$ of compound 7 (Figure 3), the stretching vibrations (1755.3 and $1771.8 \mathrm{~cm}^{-1}$ ) of the $\mathrm{C}=\mathrm{C}$ bonds in compounds 10 and 11 are blue-shifted. The electron density on the thiophene rings in compounds 10 and 11 is augmented and the $\mathrm{C}=\mathrm{C}$ bonds are strengthened thanks to the electron-donating effect of the group $-\mathrm{NH}_{2}$. The first peak at 3348.2 $\mathrm{cm}^{-1}$ of compound 11 is also blue-shifted relative to that of compound 7, which is arisen from the stretching vibrations of the N-H bonds. The number of the IR absorptions of compounds 12 and 13 is increased relative to those of compounds 1 and 6 . This is relevant to the decrease of the symmetry in compounds 1 and 6 after the phenyl rings are replaced by the thiophene rings. The first absorptions at 3301.4 and $3301.9 \mathrm{~cm}^{-1}$ of compounds 12 and 13 are blue-shifted relative to that of compound 1 , caused by the intensification of the $\mathrm{C}-\mathrm{H}$ bonds on the thiophene rings. The intensities of the absorptions within $1700-1300 \mathrm{~cm}^{-1}$ for compounds 6,12 and 13 are elevated owing to the increasing $\mathrm{C}-\mathrm{S}$ bonds.

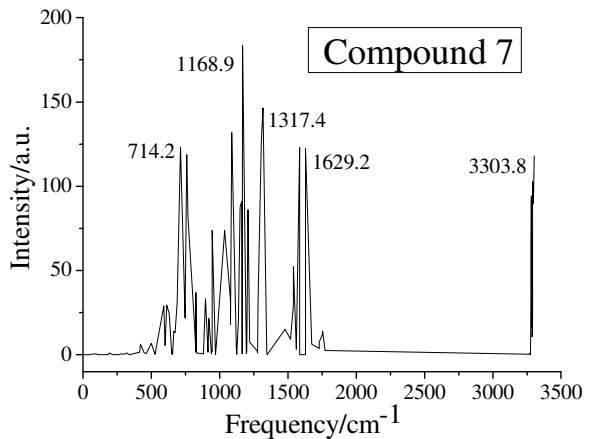

(a) The IR spectrum

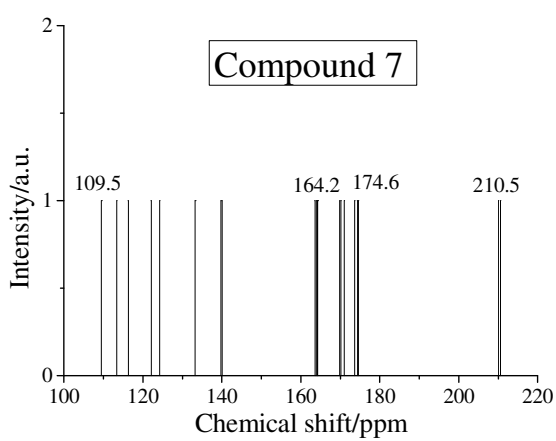

(b) The ${ }^{13} \mathrm{C}$ NMR spectrum

Figure 3. The IR and ${ }^{13} \mathrm{C}$ NMR spectra of compound 7. 
The ${ }^{13}$ C NMR spectra

There are four kinds of resonance absorptions in the ${ }^{13} \mathrm{C}$ NMR spectrum of compound 1 . These absorptions represent the carbon atoms on the phenyl rings because of the $C_{3 h}$ symmetry of compound 1 . The ${ }^{13} \mathrm{C}$ chemical shifts of compounds $2-5$ relative to the $163.9 \mathrm{ppm}$ of compound 1 are upfield to $137.4,147.6,137.3$ and $155.8 \mathrm{ppm}$, respectively. The electron density on these carbon atoms in compounds $2-5$ is enhanced and the shielding effect is strengthened in the presence of the alkyl groups. This is in agreement with the experimental result that the chemical shifts of some carbon atoms in the complexes are upfield under the effect of the electrondonating substituents [29]. The $\mathrm{sp}^{3}-\mathrm{C}$ atoms on the alkyl groups in compounds 2-5 are intensely shielded with derivative 5 being the nearest to the TMS reference as expected with their chemical shifts in the 10.6-39.7 ppm range.

The number of the resonance absorptions in compound 6 relative to that of compound 1 is increased because the phenyl rings are replaced by the thiophene rings and the molecular symmetry is reduced. The absorptions in the ranges of 164.2-210.9 and 127.2-148.9 ppm of compound 6 are produced by the carbon atoms on the phenyl and thiophene rings, respectively. The ${ }^{13} \mathrm{C}$ chemical shifts at $109.5,107.4$ and $107.1 \mathrm{ppm}$ of compounds 7,8 and 9 are upfield relative to the $127.2 \mathrm{ppm}$ of compound 6 . The newly added thiophene ring increases the electron density on the carbon atoms in the neighboring thiophene ring, leading to the intensified shield effect. The chemical shifts at 91.8 and $81.4 \mathrm{ppm}$ of compounds 10 and 11 are upfield compared with the $109.5 \mathrm{ppm}$ of compound 7 (Figure 3). The presence of $-\mathrm{NH}_{2}$ improves the shielding effect of the $\mathrm{sp}^{2}-\mathrm{C}$ atoms on the adjacent thiophene ring. Similarly, the chemical shifts at 126.0 and $126.4 \mathrm{ppm}$ of compounds 12 and 13 are upfield relative to the $127.2 \mathrm{ppm}$ of compound 6 . The electron-withdrawing character of the sulfur atom on the thiophene ring in compounds 12 and 13 increases the electron density and shielding effect of the $\mathrm{sp}^{2}-\mathrm{C}$ atoms.

\section{CONCLUSIONS}

The LUMO-HOMO energy gaps of triarylborane derivatives can be decreased by adding alkyl groups and thiophene rings. These derivatives with small energy gaps will exhibit red-shifted fluorescent wavelengths compared with that of the parent compound. The first absorption peaks in the electronic spectra and IR vibration frequencies of the $\mathrm{C}-\mathrm{C}$ and $\mathrm{C}-\mathrm{H}$ bonds for the derivatives are red-shifted in the presence of the alkyl groups and thiophene rings. The chemical

shifts for most of $\mathrm{sp}^{2}-\mathrm{C}$ atoms in the compounds are upfield owing to the intensified electron density caused by the alkyl groups, and those of the $\mathrm{sp}^{2}-\mathrm{C}$ atoms on the next thiophene rings are also upfield due to the increasing thiophene rings.

\section{REFERENCES}

1. Admassie, S.; Yacob, Z.; Zhang, F.; Mammo, W.; Yohannes, T.; Solomon, T. Bull. Chem. Soc. Ethiop. 2006, 20, 309.

2. Admassie, S.; Mammo, W.; Solomon, T.; Yohannes, T.; Andersson, M.R. Bull. Chem. Soc. Ethiop. 2005, 19, 267.

3. Matsumi, N.; Umeyama, T.; Chujo, Y. Polym. Bull. 2000, 44, 431.

4. Sundararaman, A.; Victor, M.; Varughese, R.; Jäkle, F. J. Am. Chem. Soc. 2005, 127, 13748.

5. Heilmann, J.B.; Scheibitz, M.; Qin, Y.; Sundararaman, A.; Jäkle, F.; Kretz, T.; Bolte, M.; Lerner, H.W.; Holthausen, M.C.; Wagner, M. Angew. Chem., Int. Ed. 2006, 45, 920.

6. Chujo, Y.; Takizawa, N.; Sakurai, T. J. Chem. Soc. Chem. Commun. 1994, 227. 
7. Kobayashi, H.; Sato, N.; Ichikawa, Y.; Miyata, M.; Chujo, Y.; Matsuyama, T. Synth. Metals 2003, 135, 393.

8. Sato, N.; Ogawa, H.; Matsumoto, F.; Chujo, Y.; Matsuyama, T. Synth. Metals 2005, 154, 113.

9. Qin, Y.; Pagba, C.; Piotrowiak, P.; Jäkle, F. J. Am. Chem. Soc. 2004, 126, 7015.

10. Goze, C.; Ulrich, G.; Ziessel, R. Org. Lett. 2006, 8, 4445.

11. Parab, K.; Venkatasubbaiah, K.; Jäkle, F. J. Am. Chem. Soc. 2006, 12879.

12. Dewar, M.J.S.; Zoebisch, E. G.; Healy E.F.; Stewart, J.J.P. J. Am. Chem. Soc. 1985, 107, 3902.

13. Becke, A.D. J. Chem. Phys. 1993, 98, 5648.

14. Lee, C.; Yang, W.; Parr, R.G. Phys. Rev. B 1988, 37, 785.

15. Xu, L.; Ding, Y.; Teng, Q. Bull. Chem. Soc. Ethiop. 2007, 21, 419.

16. Chen, X.; Teng, Q.; Wu, S.; Xu, L. Bull. Chem. Soc. Ethiop. 2007, 21, 263.

17. Zhang, Y.; Li, T.; Teng, Q. Chinese J. Chem. 2008, 26, 1567.

18. Wang, W.; Shao, S.; Zhou, H.; Teng, Q. Acta Phys. -Chim. Sin. 2008, 24, 1631.

19. Monajjemi, M.; Heshmat, M.; Aghaei, H.; Ahmadi, R.; Zare, K. Bull. Chem. Soc. Ethiop. 2007, 21, 111.

20. Mensah, J.B.; Gelize, M.; Atohoun, Y.G.S.; Pouchan, C. Bull. Chem. Soc. Ethiop. 2006, 20, 295.

21. Monajjemi, M.; Abedi, A.; Passdar, H. Bull. Chem. Soc. Ethiop. 2006, 20, 133.

22. Frisch, M.J.; Trucks, G.W.; Schlegel, H.B.; Scuseria, G.E.; Robb, M.A.; Cheeseman, J.R.; Montgomery, J.A.; Vreven, Jr.T.; Kudin, K.N.; Burant, J.C.; Millam, J.M.; Iyengar, S.S.; Tomasi, J.; Barone, V.; Mennucci, B.; Cossi, M.; Scalmani, G.; Rega, N.; Petersson, G.A.; Nakatsuji, H.; Hada, M.; Ehara, M.; Toyota, K.; Fukuda, R.; Hasegawa, J.; Ishida, M.; Nakajima, T.; Honda, Y.; Kitao, O.; Nakai, H.; Klene, M.; Li, X.; Knox, J.E.; Hratchian, H.P.; Cross, J.B.; Adamo, C.; Jaramillo, J.; Gomperts, R.; Stratmann, R.E.; Yazyev, O.; Austin, A.J.; Cammi, R.; Pomelli, C.; Ochterski, J.W.; Ayala, P.Y.; Morokuma, K.; Voth, G.A.; Salvador, P.; Dannenberg, J.J.; Zakrzewski, V.G.; Dapprich, S.; Daniels, A.D.; Strain, M.C.; Farkas, O.; Malick, D.K.; Rabuck, A.D.; Raghavachari, K.; Foresman, J.B.; Ortiz, J.V.; Cui, Q.; Baboul, A.G.; Clifford, S.; Cioslowski, J.; Stefanov, B.B.; Liu, G.; Liashenko, A.; Piskorz, P.; Komaromi, I.; Martin, R.L.; Fox, D.J.; Keith, T.; Al-Laham, M.A.; Peng, C.Y.; Nanayakkara, A.; Challacombe, M.; Gill, P.M.W.; Johnson, B.; Chen, W.; Wong, M.W.; Gonzalez, C.; Pople, J.A. Gaussian 03, Revision B. 01, Gaussian Inc.: Pittsburgh, PA; 2003.

23. Head, J.D.; Zerner, M.C. Chem. Phys. Lett. 1986, 131, 359.

24. Teng, Q.; Wu, S. J. Mol. Stru.: Theochem 2005, 719, 47.

25. Teng, Q.; Wu, S. J. Mol. Stru.: Theochem 2005, 756, 103.

26. Wu, S.; Teng, Q. Int. J. Quantum Chem. 2006, 106, 526.

27. Sun, H.; Teng, Q.; Wu, S.; Wang, Z. Indian J. Chem. 2006, 45A, 1345.

28. Teng, Q.; Wu, S. Int. J. Quantum Chem. 2005, 104, 279.

29. Hsu, M.A.; Chou, T.J. J. Chin. Chem. Soc. 2005, 52, 811.

30. Jenkins, I.H.; Salzner, U.; Pickup, P.G. Chem. Mater. 1996, 8, 2444. 